\title{
Risk factors for clopidogrel resistance in patients with ischemic cerebral infarction and the correlation with $A B C B 1$ gene rs1045642 polymorphism
}

\author{
JUN-FENG SU ${ }^{1}$, XIAO-HUI HU ${ }^{2}$ and CHENG-YAN LI ${ }^{1}$ \\ ${ }^{1}$ Department of Neurology, Renmin Hospital of Wuhan University, Wuhan, Hubei 430060; \\ ${ }^{2}$ Department of Neurology, Jingzhou Central Hospital, Tongji Medical College, \\ Huazhong University of Science and Technology, Jingzhou, Hubei 434020, P.R. China
}

Received February 24, 2014; Accepted October 24, 2014

DOI: $10.3892 / \mathrm{etm} .2014 .2058$

\begin{abstract}
The aim of the present study was to examine clopidogrel resistance $(\mathrm{CR})$ in patients with ischemic cerebral infarction and its potential association with a single nucleotide polymorphism (SNP; rs1045642) in the $A B C B 1$ gene. Patients with ischemic cerebral infarction received clopidogrel ( $75 \mathrm{mg} /$ day) for 7 days and were then subjected to a turbidimetric assay to determine platelet aggregation. Patients were then divided into a CR group and a clopidogrel-sensitive (CS) group. Demographic and clinical data between the two groups were compared. Multivariate logistic regression analysis was performed to determine independent risk factors of CR. PCR products were sequenced to assess $A B C B 1$ rs 1045642 SNP genotype and allele frequencies in each group. In total, 303 patients were enrolled in the study; this included $51 \mathrm{CR}$ cases (16.83\%) and $252 \mathrm{CS}$ cases (83.17\%). Several parameters, including hypertension, diabetes, calcium channel blocker (CCB), $\beta$-receptor blocking agent and proton pump inhibitor use, and creatinine, fasting blood glucose, homocysteine (HCY), high-sensitivity C-reactive protein (hs-CRP) and triglyceride levels were significantly higher in the $\mathrm{CR}$ group than in the CS group. Diabetes, hs-CRP-increased use of CCBs, and use of $\beta$-blockers were found to be independent risk factors for CR. However, ABCB1 gene rs1045642 polymorphism was not found to be an independent risk factor for CR. In conclusion, $\mathrm{CR}$ in ischemic stroke patients is associated with several independent risk factors, including diabetes, hs-CRP-increased use of CCBs, and use of $\beta$-blockers. However, $A B C B 1$ gene rs1045642 polymorphism has no correlation with CR.
\end{abstract}

Correspondence to: Dr Cheng-Yan Li, Department of Neurology, Renmin Hospital of Wuhan University, 99 Zhangzhidong Road, Wuhan, Hubei 430060, P.R. China

E-mail: lichengyandr@yeah.net

Key words: ischemic stroke, clopidogrel resistance, $A B C B 1$ gene, polymorphisms

\section{Introduction}

Clopidogrel is an anti-platelet agent used to prevent blood clots. It selectively and irreversibly inhibits the P2Y12 class of adenosine diphosphate (ADP) receptors on platelets to prevent aggregation. Although a number of studies have confirmed the clinical efficacy of clopidogrel as an anti-thrombotic agent, its efficiency in preventing platelet aggregation is not uniform in all patients. Between 4 and $44 \%$ of patients receiving this drug display a poor response $(1,2)$. The patients that fail to respond are referred to as clopidogrel resistant (3).

While the exact reason for clopidogrel resistance (CR) is not clear (4), the response to the drug is influenced by genetics and by clinical and pathophysiological factors $(5,6)$. Clopidogrel is a pro-drug. That is, before it can exert its anti-platelet activity, it must be metabolized by the liver into its active form; it is only this active metabolite of clopidogrel that is able to bind the ADP receptors on platelets to prevent aggregation (7). Intestinal epithelial cells expressing P-glycoprotein (P-gp) can influence the absorption of clopidogrel from the digestive tract into the blood, thus affecting the efficacy of the drug $(8,9)$. ABCB1 is expressed in P-gp epithelial cells (10), and the distribution of P-gp differs among individuals; this may explain the differential response of patients to clopidogrel (10). Recent studies have shown that single nucleotide polymorphisms (SNPs) within the $A B C B 1$ gene affect its degree of transcription and translation; subsequently, clopidogrel response may also be affected. Simon et al reported that the serum concentration of the active metabolite of clopidogrel is reduced in individuals with the $A B C B 1$ gene $3435 C>T$ SNP (7). Another study reported that in patients treated with clopidogrel, $A B C B 13435 \mathrm{C}>\mathrm{T}$ polymorphism, $\mathrm{T}$ allele carriers and major adverse cardiovascular events (MACE) are all closely associated with risk (11). These earlier studies focused on coronary heart disease patients, whose disease pathogenesis differs from those with ischemic stroke. Thus, in the present study, the risk factors of Chinese patients with ischemic cerebral infarction were explored and the correlation between $A B C B 1$ gene polymorphisms and $\mathrm{CR}$ was examined. The data obtained may help to improve individualized antiplatelet treatment options for the ischemic stroke population and reduce adverse side-effects. 


\section{Materials and methods}

Subjects. Patients with ischemic cerebral infarction who were seen at Jingzhou Central Hospital of Tongji Medical College, Huazhong University of Science and Technology (Jinzhou, China) between June 2013 and December 2013 were enrolled in the present study if they met the following inclusion criteria: i) older than 18 years; ii) present or past diagnosis of ischemic stroke [according to the 2010 Chinese Guidelines for the Management of Ischemic Stroke (12), with clinical symptoms and computed tomography (CT) or magnetic resonance imaging (MRI) verification]; iii) Trial of Org 10172 in Acute Stroke Treatment (TOAST) classification (13) of large artery atherosclerosis or small arteries with non-cardiac ischemic stroke. Patients who met the following exclusion criteria were not enrolled: i) 10 days of treatment with clopidogrel, ticlopidine, dipyridamole or other antiplatelet drugs, or treatment with other non-steroidal drugs; ii) $24 \mathrm{~h}$ of treatment with standard or low-molecular-weight heparin; iii) major surgery within the preceding week; iv) occurrence of any bleeding disorders or a family history of blood diseases; v) kidney or heart dysfunction or other serious systemic diseases; vi) concurrent malignancy or ongoing antitumor therapy; vii) platelet count $<150 \times 10^{12} / 1$ or $>450 \times 10^{12} / 1$, and hemoglobin $<8 \mathrm{~g} / \mathrm{l}$. The study and all procedures were approved by the ethics committee of Tongji Medical College, Huazhong University of Science and Technology, and all patients enrolled in the provided signed informed consent.

Information collection. Information was obtained from all patients on their general condition, medical history (hypertension, diabetes or coronary heart disease), personal history (smoking and drinking), laboratory tests, and use of concomitant medications, namely calcium channel blockers (CCBs), angiotensin-converting enzyme inhibitors, $\beta$-blockers, lipid-lowering drugs and proton pump inhibitors.

Determination of platelet aggregation. The turbidimetric method using optical density (light transmission aggregation, LTA) was performed to assess ADP (20 $\mu \mathrm{mol} / 1)$-induced platelet aggregation. Prior to collection of the specimens, the patients had received clopidogrel $(75 \mathrm{mg}$ ) daily for one week. Blood ( $2 \mathrm{ml}$ ) was extracted from the cubital vein of each patient in the morning on an empty stomach; two tubes of blood were filled and gently inverted to prevent clotting. Then, to prepare platelet-rich plasma (PRP), the samples were first spun at $700 \mathrm{x} g$ for $10 \mathrm{~min}$, and the sample quality, including severe hemolysis and severe lipemia, was determined. The supernatant containing PRP was removed, placed in a separate tube, and stored at room temperature until use. PRP was separated from platelet-poor plasma (PPP) by centrifugation at 2,200 x g for $10 \mathrm{~min}$. For test sampling, $300 \mu \mathrm{l}$ of each sample (PRP and PPP) was drawn, and platelet aggregation was determined using an SC-2000 platelet testing apparatus (Beijing Saikexide Technology Development Co., Ltd., Beijing, China); platelet aggregation was induced by treatment with ADP (20 $\mu \mathrm{mol} / \mathrm{l})$. A platelet aggregation rate $\geq 70 \%$ was defined as $\mathrm{CR}$, and a platelet aggregation rate $<70 \%$ was defined as clopidogrel-sensitive (CS). All experiments were performed within $3 \mathrm{~h}$.
Genomic DNA extraction and genotyping. Genomic DNA was isolated from $1 \mathrm{ml}$ peripheral blood using a TIANamp Blood DNA kit [DP318; Tiangen Technology (Beijing) Co., Ltd., Beijing, China]. Samples were stored at $-20^{\circ} \mathrm{C}$ until use. Primers used for genotyping were as follows: (rs1045642-F: 5-'GAATGTTCAGTGGCTCCGA-3' and rs1045642-R: 5'-CTCCCAGGCTGTTTATTTGA-3'). PCR amplification (BTC-1000; Bio Basic, Markham, Canada) was performed as follows: $50 \mu \mathrm{l}$ reaction volume containing template DNA $1 \mu 1$, upstream and downstream primers $1 \mu \mathrm{l}$, dNTP $10 \mathrm{mM}$ $1 \mu \mathrm{l}$, Taq Buffer $5 \mu \mathrm{l}, 25 \mathrm{mM} \mathrm{MgCl} 2,5 \mu \mathrm{l}$ Taq enzyme (5 U/ $\mu 1) 0.5 \mu \mathrm{l}$ and water $35.5 \mu \mathrm{l}$. PCR cycling conditions consisted of $95^{\circ} \mathrm{C}$ denaturation for $3 \mathrm{~min}, 35$ cycles of $94^{\circ} \mathrm{C}$ denaturation for $30 \mathrm{sec}, 56^{\circ} \mathrm{C}$ annealing for $35 \mathrm{sec}$, and $72^{\circ} \mathrm{C}$ extension for $40 \mathrm{sec}$, and finally one cycle of $72^{\circ} \mathrm{C}$ repair extension for $5 \mathrm{~min}$. PCR products were purified (SK1141 kit; Sangon Biotech, Shanghai, China), measured using a 3730 DNA sequence analyzer (Applied Biosystems, Foster City, CA, USA), and sequenced.

Statistical analysis. SPSS software package, version 17.0 (SPSS, Inc., Chicago, IL, USA) was used to conduct the statistical analysis. Quantitative data are presented as the mean \pm standard deviation or median (quartiles). According to the nature of the statistical data, classification was performed by $\chi^{2}$ test, corrected $\chi^{2}$ test or Fisher's exact test. Normality and homogeneity of variance were determined by t-test between two independent samples; non-parametric Wilcoxon test was used for this type of analysis. $\mathrm{P}<0.05$ was considered to indicate a statistically significant difference. Univariate analysis $(\mathrm{P}<0.05)$ and significant professional binary logistic regression analysis were performed to assess independent risk factors.

\section{Results}

CR and ischemic stroke risk factors, correlation of laboratory tests and concomitant medication. A total of 303 cases (93 females and 210 males) met all requirements and were included in the study. Cases ranged in age from 29 to 82 years, with a mean age of $63.65 \pm 9.60$ years. There were 51 cases $(16.83 \%)$ of CR, and 252 cases $(83.17 \%)$ were categorized into the CS group.

Univariate analysis demonstrated that several risk factors associated with ischemic stroke, including hypertension and diabetes, correlated with CR (Table I). Similarly, treatment with CCBs, $\beta$-receptor blocking agents and proton pump inhibitors was also associated with CR. Laboratory tests for creatinine (Cr), fasting blood glucose (FBG), homocysteine (HCY), high-sensitivity C-reactive protein (hs-CRP), and triglycerides also confirmed that each of these factors positively correlated with CR ( $\mathrm{P}<0.05$; Table I). CR occurred in $20 \%$ of patients with hypertension; by contrast, only $7.69 \%$ of individuals without hypertension experienced resistance to the drug. CR was also more common in diabetic patients $(54.55 \%)$ than in non-diabetic patients (12.22\%). It was also observed that CR was associated with the administration of various agents, including CCBs $\left(\chi^{2}=10.566, \mathrm{P}<0.01\right), \beta$-blockers $\left(\chi^{2}=14.052, \mathrm{P}<0.001\right)$ and proton pump inhibitors $\left(\chi^{2}=12.767, \mathrm{P}<0.001\right)$ and with several laboratory tests, including measures of $\mathrm{Cr}(\mathrm{Z}=2.286, \mathrm{P}<0.05)$, FBG $(\mathrm{Z}=3.375, \mathrm{P}<0.01), \mathrm{HCY}(\mathrm{Z}=2.31, \mathrm{P}<0.05)$, hs-CRP $(\mathrm{Z}=6.582$, 
Table I. Comparison of clinical data between the clopidogrel resistant and sensitive groups.

\begin{tabular}{|c|c|c|c|c|c|}
\hline \multirow[b]{2}{*}{ Variable } & \multirow[b]{2}{*}{ Class } & \multicolumn{2}{|c|}{ Clopidogrel } & \multirow[b]{2}{*}{ Statistics $^{\mathrm{a}}$} & \multirow[b]{2}{*}{ P-value } \\
\hline & & Sensitive $(\mathrm{n}=252)$ & Resistant $(\mathrm{n}=51)$ & & \\
\hline Gender & $\begin{array}{l}\text { Female } \\
\text { Male }\end{array}$ & $\begin{array}{r}72(77.42) \\
180(85.71)\end{array}$ & $\begin{array}{l}21(22.58) \\
30(14.29)\end{array}$ & 3.168 & 0.075 \\
\hline Hypertension & $\begin{array}{l}\text { No } \\
\text { Yes }\end{array}$ & $\begin{array}{r}72(92.31) \\
180(80.00)\end{array}$ & $\begin{array}{c}6(7.69) \\
45(20.00)\end{array}$ & 6.268 & 0.012 \\
\hline $\begin{array}{l}\text { Coronary } \\
\text { heart disease }\end{array}$ & $\begin{array}{l}\text { No } \\
\text { Yes }\end{array}$ & $\begin{array}{r}192(85.33) \\
60(76.92)\end{array}$ & $\begin{array}{l}33(14.67) \\
18(23.08)\end{array}$ & 2.927 & 0.087 \\
\hline Diabetes & $\begin{array}{l}\text { No } \\
\text { Yes }\end{array}$ & $\begin{array}{r}237(87.78) \\
15(45.45)\end{array}$ & $\begin{array}{l}33(12.22) \\
18(54.55)\end{array}$ & 37.628 & $<0.001$ \\
\hline Smoking & $\begin{array}{l}\text { No } \\
\text { Yes }\end{array}$ & $\begin{array}{r}153(80.95) \\
99(86.84)\end{array}$ & $\begin{array}{l}36(19.05) \\
15(13.16)\end{array}$ & 1.762 & 0.184 \\
\hline Drinking & $\begin{array}{l}\text { No } \\
\text { Yes }\end{array}$ & $\begin{array}{r}198(84.62) \\
54(78.26)\end{array}$ & $\begin{array}{l}36(15.38) \\
15(21.74)\end{array}$ & 1.537 & 0.215 \\
\hline $\mathrm{CCB}$ & $\begin{array}{l}\text { No } \\
\text { Yes }\end{array}$ & $\begin{array}{r}165(88.71) \\
87(74.36)\end{array}$ & $\begin{array}{l}21(11.29) \\
30(25.64)\end{array}$ & 10.566 & 0.001 \\
\hline ACEI & $\begin{array}{l}\text { No } \\
\text { Yes }\end{array}$ & $\begin{array}{r}216(84.71) \\
36(75.00)\end{array}$ & $\begin{array}{l}39(15.29) \\
12(25.00)\end{array}$ & 2.718 & 0.099 \\
\hline$\beta$-blocker & $\begin{array}{l}\text { No } \\
\text { Yes }\end{array}$ & $\begin{array}{r}237(85.87) \\
15(55.56)\end{array}$ & $\begin{array}{l}39(14.13) \\
12(44.44)\end{array}$ & 14.052 & $<0.001$ \\
\hline Statin & $\begin{array}{l}\text { No } \\
\text { Yes }\end{array}$ & $\begin{array}{c}15(100.00) \\
237(82.29)\end{array}$ & $\begin{array}{c}0(0.00) \\
51(17.71)\end{array}$ & 2.054 & 0.152 \\
\hline Proton pump inhibitor & $\begin{array}{l}\text { No } \\
\text { Yes }\end{array}$ & $\begin{array}{r}234(85.71) \\
18(60.00)\end{array}$ & $\begin{array}{l}39(14.29) \\
12(40.00)\end{array}$ & 12.767 & $<0.001$ \\
\hline Age (years) & & $63(56.5,71)$ & $67(62,69)$ & 1.941 & 0.052 \\
\hline BUN (mmol/l) & & $5.03(4.05,6.23)$ & $4.2(3.85,5.82)$ & -1.561 & 0.119 \\
\hline $\mathrm{Cr}(\mathrm{umol} / \mathrm{l})$ & & $72.95(59.15,88.1)$ & $79.1(60.9,111.5)$ & 2.286 & 0.022 \\
\hline UA (umol/l) & & $319.9(255.15,391.85)$ & $367.3(273.5,429.1)$ & 1.845 & 0.065 \\
\hline FBG $(\mathrm{mmol} / \mathrm{l})$ & & $5.57(5.11,6.57)$ & $6.11(5.49,8.02)$ & 3.375 & 0.001 \\
\hline HCY (umol/l) & & $15.92(13.44,21.28)$ & $19.46(15.46,22.65)$ & 2.31 & 0.021 \\
\hline hs-CRP (mg/l) & & $0.95(0.5,2.65)$ & $4.21(2.21,11.97)$ & 6.582 & $<0.001$ \\
\hline Cholesterol (mmol/l) & & $4.72(3.87,5.59)$ & $4.96(3.82,5.34)$ & -0.449 & 0.654 \\
\hline Triglycerides (mmol/l) & & $1.31(0.95,2.05)$ & $1.39(1.23,2.83)$ & 2.35 & 0.019 \\
\hline $\operatorname{HDL}(\mathrm{mmol} / \mathrm{l})$ & & $1.04(0.91,1.25)$ & $1.08(0.89,1.34)$ & 0.614 & 0.539 \\
\hline $\mathrm{LDL}(\mathrm{mmol} / \mathrm{l})$ & & $2.68(1.98,3.39)$ & $2.7(2,2.92)$ & -1.679 & 0.093 \\
\hline Platelet count $\left(\times 10^{9}\right)$ & & $157.5(135.15,193.7)$ & $173(127,206.3)$ & 0.299 & 0.765 \\
\hline
\end{tabular}

CCB, calcium channel blocker; ACEI, angiotensin-converting enzyme inhibitor; BUN, blood urea nitrogen; Cr, creatinine; UA, uric acid; FBG, fasting blood glucose; HCY, homocysteine; hs-CRP, high-sensitivity C-reactive protein; HDL, high-density lipoprotein; LDL, low-density

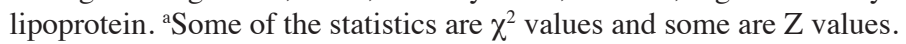

$\mathrm{P}<0.01)$ and triglycerides $(\mathrm{Z}=2.35, \mathrm{P}<0.05)$. No significant association was identified between response to clopidogrel and gender, coronary heart disease or smoking.

Univariate analysis identified several statistically significant independent variables, including hypertension, diabetes, CCBs, $\beta$-receptor blocking agents, proton pump inhibitors,
Cr, FBG, HCY, hs-CRP, and triglycerides which were associated with $\mathrm{CR}$ as dependent variables. Controlling for gender, smoking and other factors, binary logistic regression analysis identified several additional independent risk factors associated with $\mathrm{CR}$, including $\mathrm{CCBs}, \beta$-blockers, hs-CRP and diabetes (Table II). 
Table II. Logistic regression analysis.

OR, $95 \% \mathrm{CI}$

\begin{tabular}{lrrrrrrr} 
Variable & \multicolumn{1}{c}{ B } & SE & Walds & df & P-value & OR & Limit \\
\hline CCB & 1.137 & 0.359 & 10.046 & 1 & 0.002 & 3.117 & 1.543 \\
$\beta$-blockers & 1.406 & 0.497 & 8.022 & 1 & 0.005 & 4.081 & 1.542 \\
hs-CRP & .056 & 0.018 & 9.463 & 1 & 0.002 & 1.058 & 1.021 \\
Diabetes & 2.149 & 0.442 & 23.597 & 1 & 0.000 & 8.575 & 3.603 \\
Constant & -3.039 & 0.333 & 83.446 & 1 & 0.000 & 0.048 & 1.097 \\
\hline
\end{tabular}

CCB, calcium channel blocker.; hs-CRP, high-sensitivity C-reactive protein; SE, standard error; df, degree of freedom; OR, odds ratio; CI, confidence interval.

Table III. ABCB1 rs1045642 genotype distribution and allele frequencies.

\begin{tabular}{|c|c|c|c|c|}
\hline Genotype and allele & $\begin{array}{l}\text { Clopidogrel resistance } \\
\qquad(\mathrm{n}=51)\end{array}$ & $\begin{array}{l}\text { Clopidogrel sensitive } \\
\qquad(\mathrm{n}=252)\end{array}$ & $\chi^{2}$ value & P-value \\
\hline $\mathrm{CC}, \mathrm{n}(\%)$ & $27(23.7)$ & $87(76.3)$ & 10.383 & 0.006 \\
\hline $\mathrm{TT}, \mathrm{n}(\%)$ & $6(28.6)$ & $15(71.4)$ & & \\
\hline $\mathrm{CT}, \mathrm{n}(\%)$ & $18(10.7)$ & $150(89.3)$ & & \\
\hline $\mathrm{C}, \mathrm{n}(\%)$ & $72(18.2)$ & $324(81.8)$ & 1.488 & 0.223 \\
\hline $\mathrm{T}, \mathrm{n}(\%)$ & $30(14.3)$ & $180(85.7)$ & & \\
\hline
\end{tabular}

Correlation among ischemic stroke, ABCB1 gene rs1045642 polymorphism and $C R$. Polymorphisms of the $A B C B 1$ gene (rs1045642) are shown in Table III. The two polymorphisms were found to be in Hardy-Weinberg equilibrium. Univariate analysis revealed that there was a significant difference between the $\mathrm{CR}$ and $\mathrm{CS}$ groups $\left(\mathrm{P}=0.006, \chi^{2}=10.383\right)$. Moreover, there were different associations between each of the genotypes and response to clopidogrel. For example, there was no significant difference in the $\mathrm{C}, \mathrm{T}$ allele frequency between the $\mathrm{CR}$ and $\mathrm{CS}$ groups $\left(\mathrm{P}=0.223, \chi^{2}=1.488\right)$. Controlling for gender, smoking, and other factors, binary logistic regression analysis was performed and it was found that none of the three genotypes were independent risk factors for $\mathrm{CR}(\mathrm{P}=0.0192, \mathrm{P}=0.070$ and $\mathrm{P}=0.118)$.

\section{Discussion}

The majority of previous studies examining CR have focused on individuals with cardiovascular disease. By contrast, less is known about the response to clopidogrel in patients suffering from ischemic stroke. In the present study, a $16.83 \%$ incidence of CR was observed, which is consistent with the rates published in the literature $(4-44 \%)(1,2)$. However, there are differences between cardiovascular and cerebrovascular conditions that is it necessary to address.

The exact mechanisms responsible for CR are unknown. However, several studies have shown that self-compliance, inadequate dosing, absorption or metabolic dysfunction, drug interactions, diabetes, vascular factors, and genetic factors may all influence the response to the drug (14-17). Other studies have shown a decreased response to clopidogrel in patients with elevated levels of glycated hemoglobin and C-peptide $(18,19)$. Diabetes has also been described as an independent risk factor for CR (20). In the present study, it was found that the long-term use of CCBs, hs-CRP and $\beta$-blockers is associated with CR. While the association between CCBs and clopidogrel has been previously reported (21), to the best of our knowledge, this is the first time any correlations between $\beta$-blockers, hs-CRP and clopidogrel response have been described. These findings suggest that patients with these factors should be given more attention, with regular testing for platelet aggregation. It is important to identify patients with $\mathrm{CR}$, as they may benefit from additional anti-platelet drugs to prevent recurrent stroke.

Recent studies have focused on the identification of potential correlations between CR and genetic polymorphisms $(22,23)$. Clopidogrel is a pro-drug that must be metabolized to its active form. Two genes important for drug metabolism are $A B C B 1$ and $C Y P 2 C 19$. CYP2C19 has been previously linked to $\mathrm{CR}$ (24,25). Associations between $A B C B 1$ and CR are not as well established and studies have reported conflicting results. One study found that patients with the $A B C B 1$ TT genotype at the rs1045642 locus had a higher risk of recurrent ischemic events following clopidogrel treatment; those with the wild-type CC genotype did not experience this increased rate of recurrence (11). In contrast to these findings, another study reported that individuals with the wild-type CC genotype had a higher risk of recurrent ischemic events following clopidogrel treatment (26). Importantly, these earlier studies focused on coronary heart disease patients and not on stroke sufferers. In the present 
study, the potential correlation between $A B C B 1$ genotype and ischemic stroke recurrence was examined in patients treated with clopidogrel. Notably, no significant correlation was identified among these variables. This could be due to confounding factors. Additionally, a single polymorphic locus may not be directly responsible for the effect; instead, an analysis of multiple polymorphic loci may require consideration.

In conclusion, the data presented in the present study suggest that several patient characteristics should be considered prior to the administration of clopidogrel. This would help distinguish patients that are likely to respond to the drug from those that would likely be resistant. While this study is promising, it is partly limited by its small sample size. It should be followed up by another multi-center clinical trial with a greater number of patients in order to confirm and verify these findings.

\section{References}

1. Dupont AG, Gabriel DA, Cohen MG. Antiplatelet therapies and the role of antiplatelet resistance in acute coronary syndrome. Thromb Res 124: 6-13, 2009.

2. Gurbel PA and Tantry US: Clopidogrel resistance? Thromb Res 120: 311-321, 2007.

3. Yang $\mathrm{R}$ and $\mathrm{Wu} \mathrm{F}$ : The progress of research on clopidogrel resistance. Int J Intern Med 36: 428-431, 2009 (In Chinese).

4. Ford NF: Clopidogrel resistance: pharmacokinetic or pharmacogenetic? J Clin Pharmacol 49: 506-512, 2009

5. Kolandaivelu K and Bhatt DL: Overcoming 'resistance' to antiplatelet therapy: targeting the issue of nonadherence. Nat Rev Cardiol 7: 461-467, 2010.

6. Holmes MV, Perel P, Shah T, Hingorani AD and Casas JP: CYP2C19 genotype, clopidogrel metabolism, platelet function and cardiovascular events: a systematic review and meta-analysis. JAMA 306: 2704-2714, 2011

7. Simon T, Verstuyft C, Mary-Krause M, Quteineh L, Drouet E, Méneveau N, Steg PG, Ferrières J, Danchin N and Becquemont L; French Registry of Acute ST-Elevation and Non-ST-Elevation Myocardial Infarction (FAST-MI) Investigators: Genetic determinants of response to clopidogrel and cardiovascular events. N Engl J Med 360: 363-375, 2009.

8. Taubert D, von Beckerath N, Grimberg G, et al: Impact of P-glycoprotein on clopidogrel absorption. Clin Pharmacol Ther 80: 486-501, 2006.

9. Gros P, Ben Neriah YB, Croop JM and Housman DE. Isolation and expression of a complementary DNA that confers multidrug resistance. Nature 323: 728-731, 1986:

10. Sakaeda T, Nakamura T and Okumura K: MDR1 genotype-related pharmacokinetics and pharmacodynamics. Biol Pharm Bull 25: 1391-1400, 2002.

11. Mega JL, Close SL, Wiviott SD, Shen L, Walker JR, Simon T, Antman EM, Braunwald E and Sabatine MS: Genetic variants in ABCB1 and CYP2C19 and cardiovascular outcomes after treatment with clopidogrel and prasugrel in the TRITON-TIMI 38 trial: a pharmacogenetic analysis. Lancet 376: 1312-1319, 2010
12. Neurology Committee of the Chinese Medical Association for cerebrovascular disease diagnosis and treatment guidelines for ischemic stroke: Chinese diagnosis and treatment guidelines for ischemic stroke 2010. Chin J Neurol 43: 146-153, 2010.

13. Adams HP Jr, Bendixen BH, Kappelle LJ, Biller J, Love BB, Gordon DL and Marsh EE III: Classification of subtype of acute ischemic stroke. Definitions for use in a multicenter clinical trial. TOAST. Trial of Org 10172 in Acute Stroke Treatment. Stroke 24: 35-41, 1993

14. Mega JL, Close SL, Wiviott SD, et al: Cytochrome p-450 polymorphisms and response to clopidogrel. N Engl J Med 360: 354-362, 2009.

15. Sibbing D, Morath T, Stegherr J, Braun S, Vogt W, Hadamitzky M, Schömig A, Kastrati A and von Beckerath N: Impact of proton pump inhibitors on the antiplatelet effects of clopidogrel. Thromb Haemost 101: 714-719, 2009.

16. Montalescot G, Sideris G, Meuleman C, et al: A randomized comparison of high clopidogrel loading doses in patients with non-ST-segment elevation acute coronary syndromes: the ALBION (Assessment of the Best Loading Dose of Clopidogrel to Blunt Platelet Activation, Inflammation and Ongoing Necrosis) trial. J Am Coll Cardiol 48: 931-938, 2006.

17. Lepäntalo A, Virtanen KS, Heikkilä J, Wartiovaara U and Lassila R: Limited early antiplatelet effect of $300 \mathrm{mg}$ clopidogrel in patients with aspirin therapy undergoing percutaneous coronary interventions. Eur Heart J 25: 476-483, 2004.

18. Hall HM, Banerjee S and McGuire DK: Variability of clopidogrel response in patients with type 2 diabetes mellitus. Diab Vasc Dis Res 8: 245-253, 2011.

19. Angiolillo DJ and Suryadevara S: Aspirin and clopidogrel: efficacy and resistance in diabetes mellitus. Best Pract Res Clin Endocrinol Metab 23: 375-388, 2009.

20. Angiolillo DJ, Fernandez-Ortiz A, Bernardo E, et al:Platelet function profiles in patients with type 2 diabetes and coronary artery disease on combined aspirin and elopidogrel treatment. Diabetes 54: 2430-2435, 2005

21. Gurbel PA, Antonino MJ and Tantry US: Recent developments in clopidogrel pharmacology and their relation to clinical outcomes. Expert Opin Drug Metab Toxicol 5: 989-1004, 2009.

22. Kubica A, Kozinski M, Grzesk M, et al. Genetic determinants of platelet response to clopidogrel. J Thromb Thrombolysis 32: 459-466, 2011.

23. Delaney JT, Ramirez1 AH, Bowton E, Pulley JM, Basford MA, Schildcrout JS, Shi Y, Zink R, Oetjens M, Xu H, Cleator JH, Jahangir E, Ritchie MD, Masys DR, Roden DM, Crawford DC and Denny JC: Predicting clopidogrel response using DNA samples linked to an electronic health record. Clin Pharmacol Ther 91: 257-263, 2012.

24. Yang J, Zhao HD, Tan J, Ding YL, Gu ZQ and Zou JJ: CYP2C19 polymorphism and antiplatelet effects of clopidogrel in Chinese stroke patients. Pharmazie 183-186, 2013.

25. Nyírő G, Inczédy-Farkas G, Reményi V, et al. The effect of the CYP 2 C19*2 polymorphism on stroke care. Acta Physiol Hung 99: 33-39, 2012.

26. Wallentin L, James S, Storey RF, Armstrong M, Barratt BJ, Horrow J, Husted S, Katus H, Steg PG, Shah SH and Becker RC; PLATO investigators: Effect of CYP2C19 and ABCB1 single nucleotide polymorphisms on outcomes of treatment with ticagrelor versusclopidogrel for acute coronary syndromes: a genetic substudy of the PLATO trial. Lancet 376: 1320-1328, 2010 . 